\title{
THE TRAGEDY OF CLIMATE CHANGE
}

\author{
ROBERT I MCLACHLAN
}

\begin{abstract}
Reviews the discovery of the phenomenon of the tragedy of the commons, from Marco Polo, through William Foster Lloyd in 1833, H Scott Gordon in 1954, and Garrett Hardin in 1968; it is argued that the first known realization that anthropogenic climate change is a global tragedy of the commons by Chen, Winter, and Bergman in 1980, was ahead of its time and was, sadly, insufficiently recognized. It is argued that the tragedy of the commons framing was slow to be discovered, to be appreciated, and has yet to achieve widespread popular recognition. Its contemporary relevance is illustrated through a discussion of recent work of Thomas Hale.
\end{abstract}

Climate change is a tragedy four ways.

First, its effects are tragic. The loss of coastal cities ancient and modern, the massive impact on biodiversity (the coral reef ecosystems are going now), the geopolitical disruption and human suffering, these will all be tragic in the everyday sense. They are massive and hard to fully grasp.

Second, climate change is tragic in the classical sense that it is in some ways inevitable. The flaw is baked into the initial conditions. All that carbon lying around just below the surface (or in some cases, actually on the surface) and all that oxygen ready and waiting just above. They were bound to react; the situation was only barely stable.

Marco Polo, writing in the 13th century:

Concerning the black stones that are dug

in Cathay, and are burnt for fuel.

It is a fact that all over the country of Cathay there is a kind of black stones existing in beds in the mountains, which they dig out and burn like firewood. If you supply the fire with them at night, and see that they are well kindled, you will find them still alight in the morning; and they make such capital fuel that no other is used throughout the country. It is true that they have plenty of wood also, 
but they do not burn it, because those stones burn better and cost less.

Moreover with that vast number of people, and the number of hot baths that they maintain-for every one has such a bath at least three times a week, and in winter if possible every day, whilst every nobleman and man of wealth has a private bath for his own use-the wood would not suffice for the purpose.

Those stones burn better and cost less. Considering the story of human cultural evolution and indeed the evolution of all life, the universe, and everything as one of greater and greater throughput of energy, it seems inevitable that this energy source was bound to be exploited sooner or later.

Third, climate change features tragic irony in that the audience - us - knows full well what the situation is and what the risks are. Not only was global warming discovered in the 19th century, the majority of greenhouse gas emissions have taken place since 1980 during a period of intense focus on solutions. The solutions, renewable energy and carbon charges, appear to be fully up to the task, making the whole thing look (tragically) preventable.

These three factors, the disaster, the inevitability, and the preventability, are all bundled up in the fourth tragedy, the tragedy of the commons. Self-interest will deplete a freely available shared resource, against each of the parties' longterm interest.

Developed by Garrett Hardin in 1968, the phenomenon of the tragedy of the commons was discovered in 1833, by the Oxford economist William Foster Lloyd, in a rebuttal to Adam Smith. In high school I learned about the invisible hand of Adam Smith; I didn't learn about the commons. Today, climate change is generally viewed as a global, intergenerational tragedy of the commons. Environmentalists know about it, economists know about it. In a major project to reform first-year biology courses, John Moore wrote in 1985, "Hardin's Tragedy of the Commons should be required reading for all students... and if I had my way, for all human beings". Another 34 years on, does everyone know about it?

Far from being obvious, the commons model did not spread quickly to the study of climate change. One of very few early works that interprets climate change mitigation in terms of the commons is a wide-ranging 1980 paper by Chen, Winter, and Bergman. They write: 
The high degree of uncertainty, a potential for global consequences, the probability of having 'winners' and 'losers', an inability of any nation to 'solve' the problem alone, the need for new levels of international cooperation not only to identify the problem but also to act upon it, the complexity of the problem, and the feeling of helplessness in avoiding the potential consequences of increasing levels of atmospheric $\mathrm{CO}_{2}$ place it among the set of the tragedy of the commons problems that seem to be emerging with increasing frequency. Such problems both require and provide opportunities for learning new ways of problem solving as a global society. We need to develop and provide the resources necessary to address problems of this kind. Such problems can be approached in four steps, of increasing effectiveness:

compensatory - paying for the damage;

ameliorative - replacing or substituting for that which is damaged;

preventive - not allowing damage to occur;

systemic - changing the mode and process of problem solving or re-

defining the problem in a categorically different fashion.

Unfortunately, that paper received only four citations: in other words, it bombed. The trail went cold.

In a recent Scientific American blog post, Matto Mildenberger rightly draws attention to Hardin's links with white nationalism and his extremist political and ethical views. But of the 'discovery' of the tragedy of the commons, he also writes, "Let's not credit Hardin for that common insight." However, like many simple ideas that eventually seem obvious, this insight was neither common, nor were its implications quickly realized.

Lloyd's work remained almost entirely unknown for a long time. It was hardly cited at all in the 19th century, and only mentioned a few times in 20th century population studies. Possibly Hardin discovered it through George McCleary's 1953 book The Malthusian Population Theory, which was reviewed in a few economics journals. But by 1968 it was scarcely well known.

Yes, Hardin had precursors. A key early example is the Canadian-American economist H Scott Gordon, who wrote in 1954:

There appears, then, to be some truth in the conservative dictum that everybody's property is nobody's property. Wealth that is free for all is valued by none because he who is foolhardy enough to wait for its proper time of use will only find that it has been taken by another. 
The blade of grass that the manorial cowherd leaves behind is valueless to him, for tomorrow it may be eaten by another's animal; the oil left under the earth is valueless to the driller, for another may legally take it; the fish in the sea are valueless to the fisherman, because there is no assurance that they will be there for him tomorrow if they are left behind today. A factor of production that is valued at nothing in the business calculations of its users will yield nothing in income. Common-property natural resources are free goods for the individual and scarce goods for society. Under unregulated private exploitation, they can yield no rent; that can be accomplished only by methods which make them private property or public (govern-ment) property, in either case subject to a unified directing power.

Pretty good. Except, in climate change, "no rent" means "a destroyed planet". Gordon's paper was long and technical and had little immediate impact outside economics - specifically, the economics of fishing, the subject of his paper.

During the 1970s there were numerous popular articles on global warming and other aspects of the energy crisis, but they did not feature the crucial aspect of the tragedy of the commons. Consider the influential 1970 Scientific American article The Carbon Cycle by Bert Bolin. Despite a good discussion of the present and future rise in atmospheric carbon dioxide from the burning of fossil fuels, it doesn't mention the greenhouse effect or global warming at all. The article concludes:

The greatest disturbances of which we are aware are those now being introduced by man himself. Since his tampering with the biological and geochemical balances may ultimately prove injurious-even fatal-to himself, he must understand them much better than he does today. The story of the circulation of carbon in nature teaches us that we cannot control the global balances. Therefore we had better leave them close to the natural state that existed until the beginning of the Industrial Revolution. Out of a simple realization of this necessity may come a new industrial revolution.

A followup SA article of January 1978, The Carbon Dioxide Question by George Woodwell, concentrating on the great uncertainties in the global carbon budget, had only this to say on political aspects: "Whether such drastic measures [afforestation and the curtailing the burning of fossil fuels] could be effected is much in doubt; the social problems that would result would clearly be profound." 
The commons picture did not spread to popular consciousness until the late 1980s, perhaps triggered by James Hansen's 1988 testimony to Congress.

In fact, even today, popular accounts do not always adopt this framework. Of two recent best-selling books, Naomi Klein's This Change Everything does not mention the tragedy of the commons at all, and Kate Raworth's Doughnut Economics only brings it up in order to mock it as a neoliberal plot.

Similarly, in my view Mildenberger mischaracterizes the whole phenomenon. The main actors in the tragedy of the commons are not individuals, but fossil fuel companies and nations. They really are acting in their own (short-term) self interest and depleting an unmanaged resource, against the common interest of all. It's a fundamental economic fact.

Mildenberger goes so far as to declare that "climate change is not a tragedy of the commons," and that we should ditch the whole 'metaphor'. The source for this was a recent paper by Thomas Hale from the University of Oxford. However, that paper says nothing of the kind. It's a piece of research framed squarely in the long tradition of commons management studies. Hale calls climate change mitigation "a quintessential global commons problem," which may, in fact, "still be a tragedy of the commons at the global scale," and that some actors, such as fossil fuel companies, are in fact enmeshed in the classic tragedy of the commons.

Hale's contribution is to study three ways in which climate change mitigation differs from the simplest model, namely (i) joint goods (some actions yield private as well as public benefits); (ii) preference diversity (some actors are much more willing to act than others); and (iii) increasing returns (action now makes future action and future collectivity easier.) He discusses in detail how the Paris Agreement and Elinor Ostrom's multilevel approach (featuring individual, community, corporate, civic, regional, national, and global actors) embody these aspects. Indeed, reading Hale's paper you may see ways in which these three factors are present in your own experience of climate action. Together they form a framework that Hale calls "catalytic cooperation" that gives climate advocates a useful additional strategy.

After fifty years, research in the management of the commons is continuing to yield vital insights. Nothing in climate change mitigation makes sense except in light of the tragedy of the commons. As it was fifty years ago, so it is today, the phenomenon of the commons should be common knowledge to all, that tragedy might yet be averted. 


\section{References}

John Moore, Science as a way of knowing-human ecology, American Zoologist25, no. 2 (1985): 483-637.

H Scott Gordon, The economic theory of a common-property resource: the fishery. In Classic Papers in Natural Resource Economics(pp. 178-203). Palgrave Macmillan, London, 1954.

Eric Chaisson, Energy rate density as a complexity metric and evolutionary driver, Complexity 16, no. 3 (2011): 27-40.

Ken Chen, Richard Winter, and Michael Bergman, Carbon dioxide from fossil fuels: Adapting to uncertainty, Energy Policy 8, no. 4 (1980): 318-330.

Matto Mildenberger, The tragedy of the tragedy of the commons,

Bert Bolin, The carbon cycle, Scientific American 223, no. 3 (1970): 124-35. .

George Woodwell, The carbon dioxide question, Scientific American 238, no. 1 (1978): 34-43. .

Thomas Hale, Catalytic cooperation, working paper.

MASSEY UNIVERSITY 